\title{
THE
}

2008

\section{Growth Trajectories of Preterm Infants: Birth to 12 Years}

\author{
Mary C. Sullivan \\ University of Rhode Island, mcsullivan@uri.edu \\ Margaret M. McGrath \\ University of Rhode Island, mmcgrath@uri.edu \\ Katheleen Hawes \\ University of Rhode Island
}

Barry M. Lester

Follow this and additional works at: https://digitalcommons.uri.edu/nursing_facpubs

This is a pre-publication author manuscript of the final, published article.

Creative Commons License

\section{c) (i) $\ominus$}

This work is licensed under a Creative Commons Attribution-Noncommercial-No Derivative Works 4.0 License.

\section{Citation/Publisher Attribution}

Sullivan, M. C., McGrath, M. M., Hawes, K., \& Lester, B. M. (2008). Growth Trajectories of Preterm Infants: Birth to 12 Years. Journal of Pediatric Health Care, 22(2), 83-93. doi: 10.1016/j.pedhc.2007.02.008 Available at: https://doi.org/10.1016/j.pedhc.2007.02.008

This Article is brought to you for free and open access by the College of Nursing at DigitalCommons@URI. It has been accepted for inclusion in College of Nursing Faculty Publications by an authorized administrator of DigitalCommons@URI. For more information, please contact digitalcommons-group@uri.edu. 


\title{
Growth Trajectories of Preterm Infants: Birth to 12 Years
}

\author{
Mary C. Sullivan, PhD, RN [Professor] \\ Margaret M. McGrath, DNSc, RN [Professor Emeritus] \\ University of Rhode Island, College of Nursing, Kingston, RI \\ Katheleen Hawes, MS, APRN [Doctoral Student] \\ University of Rhode Island, College of Nursing, Kingston, RI \\ Barry M. Lester, PhD [Professor; Director] \\ Brown Medical School, Providence, RI \\ Brown Center for the Study of Children at Risk, Providence, RI
}

University of Rhode Island, College of Nursing, Kingston, RI, and Research Scientist, Brown Center for the Study of Children at Risk, Brown Medical School, Women \& Infants Hospital, Providence, RI

\begin{abstract}
Introduction-Birth weight often is used to predict how preterm infants will grow, but scant attention has been paid to the effect of neonatal morbidities on growth trajectories. We investigated birth weight and neonatal morbidity in preterm infants' growth to age 12 years.

Method-A five-group, prospective, longitudinal study was conducted with 194 infants: 46 full term; 29 healthy preterm without morbidity; 56 preterm with medical illness (MPT); 34 preterm with neurologic illness; and 29 preterm small for gestational age (SGA). Height, weight, and body mass index were measured at six ages.

Results-The full-term group had greater height than the preterm groups to age 8 years, when healthy preterm and MPT groups caught up. Only the SGA group had smaller height at age 12 years. The MPT, preterm with neurologic illness, and SGA groups had lower weight through age 12 years. Body mass index was appropriate for preterm groups by age 4 years. Across time, neonatal morbidity had a significant effect on height and weight trajectories. Birth weight was significant for weight trajectories only.
\end{abstract}

Discussion-With variation in growth trajectories, details of neonatal morbidity in health history interviews will inform child health assessments.

Wide-ranging differences in growth exist between full-term (FT) children born with normal birth weight and those born prematurely. With the exception of infants with severe impairment, infants weighing less than $1500 \mathrm{~g}$ are likely to remain smaller. There is evidence of "catch-up" growth for preterm children at school age (6-9 years) when growth is comparable with their normal birth weight peers (Albertsson-Wiklund \& Karlberg, 1994; Hack, Weissman, \& Borawski-Clark, 1996). Infants born at weights categorized as very low birth weight (VLBW; $1000-1499 \mathrm{~g}$ ) and extremely low birth weight (ELBW; < $1000 \mathrm{~g}$ ) remain smaller than their normal birth weight peers at adolescence (Ford, Doyle, Davis, \& Callanan, 2000; PeraltaCarcelen et al., 2000; Powls, Botting, Cooke, Pilling, \& Marlow, 1996; Saigal, Stoskopf, Striener, \& Burrows, 2001). Factors predicting or correlating with growth attainment in preterm

Copyright (@) 2008 by the National Association of Pediatric Nurse Practitioners

Reprint requests: Dr. Mary C. Sullivan, University of Rhode Island, College of Nursing, White Hall, Kingston, RI 02881; mcsullivan@uri.edu.. 
children include birth weight, small for gestational age (SGA) status (Ford et al.; Powls et al.; Saigal et al.), neurologic impairment and neonatal illnesses, parental height (AlbertssonWiklund \& Karlberg, 1994; Powls et al.; Saigal et al.), and social class (Vrlenich et al., 1995). As for sex, Hack et al. (2003) speculated that the higher incidence of neonatal complications in males may be one factor explaining why they showed less growth than females at age 20 years.

The combination of one or more neonatal morbidities and a long neonatal intensive care unit (NICU) course creates complex physiological stress to an immature system. Preterm infants display autonomic and regulatory behaviors indicative of stress, and some intervention studies in which NICU environmental stressors were reduced have shown improved weight gain (Ferber et al., 2002). However, little or merely secondary consideration has been given to the role of neonatal complications in growth trajectories, particularly beyond early school age.

In this study, we examined the longitudinal effect of neonatal morbidity on preterm growth from birth to age 12 years. We have investigated two issues. The first is whether growth (i.e., height, weight, and body mass index [BMI]) was different for prematurely born infants compared with FT healthy children. These preterm infants comprise four different neonatal morbidity groups. The second issue we examined was whether birth weight modifies the effects of these neonatal morbidity exposures. This is a five-group prospective design in which height, weight, and BMI were measured at six time points: birth, 18 months, 30 months, 4 years, 8 years, and 12 years. Understanding the individual and combined influence of neonatal morbidity and birth weight on preterm growth over time may explain why some preterm children remain smaller than their full-term peers and inform pediatric professionals who counsel parents of preterm infants.

\section{Methods}

\section{Sample}

This was a prospective, longitudinal study of 194 infants. For recruitment, potential preterm infants were identified from a medical chart screening during the mother's postpartum stay or during the infant's NICU stay. The FT infants were identified during the postpartum period and in the same time frame (1985-1989) as the preterm infants. The criteria for recruitment were neonatal diagnoses, birth weight less than $1850 \mathrm{~g}$, maternal mental health (no history of mental illness), and English as a primary language. Parent(s) then were invited to participate by research nurses. Fewer than $10 \%$ of the parent(s) declined participation. Institutional Review Board approval was obtained from both the hospital and university at each study time point. Parents gave informed consent each time, while children signed assent at ages 8 and 12 years.

Five study groups were determined by neonatal morbidity status: a group of healthy FT infants recruited from the hospital nursery with uncomplicated pregnancy, labor, and delivery; a group of healthy preterm infants (HPT) without medical or neurologic illness; a group of medical preterm infants (MPT) with clinical illness but without neurologic abnormality (e.g., bronchopulmonary dysplasia [BPD], respiratory distress syndrome [RDS], necrotizing enterocolitis [NEC], sepsis); a group of neurologic preterm infants (NPT) with severe neurologic illness (e.g., meningitis, hydrocephalus, grade 3 or 4 intraventricular hemorrhage $[\mathrm{IVH}]$ ); and a group of SGA preterm infants with or without medical problems. SGA was defined as less than 10th percentile weight for gestational age (Lubchenco, Hansman, \& Boyd, 1966). BPD was defined as oxygen requirement at 28 days of life. RDS required diagnosis within the first 2 days, based on typical signs (grunting and retractions) and characteristic chest radiograph findings. NEC was classified using Bell's criteria (Bell et al., 1978). Sepsis was defined as high clinical suspicion when antepartum antibiotics had been administered plus all 
culture positive episodes. IVH was classified according to the highest Papile grade (Papile, Burstein, Burstein, \& Koffler, 1978).

Understanding the individual and combined influence of neonatal morbidity and birth weight on preterm growth over time may explain why some preterm children remain smaller than their full-term peers and inform pediatric professionals who counsel parents of preterm infants.

Socioeconomic status (SES) was estimated so that there were approximately equal numbers of high, middle, and low status infants in each of the five study groups. The infants, both FT and preterm, received the standard of care at the time.

\section{Measurement}

Infant birth measures and neonatal illness were recorded from medical charts. Infant risk was measured by the Hobel neonatal scale (Hobel, Hyvarien, Okada, \& Oh, 1973), which evaluates the presence of neonatal illness related to the systems of the body (i.e., respiratory, circulatory, hematologic, and metabolic). Each item is given a weighted score with the resulting total score representing the total risk for the infant, with higher scores indicating higher risk. Two NICU advanced practice nurses extracted the neonatal data and calculated the Hobel score, and they maintained an interrater reliability agreement of $97 \%$.

Height and weight measurements were converted to sex- and age-specific percentiles and $z$ scores using the ANTHRO (Sullivan \& Gorstein, 1999) anthropometry software program, based on the Centers for Disease Control and Prevention (CDC) National Center for Health Statistics growth data in Atlanta, Ga. BMI also was calculated with the ANTHRO program. Babson and Benda (1976) percentiles for gestational age were used for the preterm infants at birth. BMI $\left(\mathrm{wt} / \mathrm{ht}^{2}\right)$, calculated from weight and height measurements, is used to judge whether weight is appropriate for height. The National Association of Pediatric Nurse Practitioners (NAPNAP), the American Academy of Pediatrics, and the American Academy of Family Physicians endorse universal screening using BMI and the use of BMI growth curves to identify obese and overweight children (Moyer et al., 2005; NAPNAP, 2006).

\section{Growth Assessment}

In addition to recruitment and assessment at birth, children were seen at 18 months, 30 months, 4 years, 8 years, and 12 years as part of a research follow-up study of prematurity on developmental outcomes. We corrected for gestational age up to 30 months. A health history and physical assessment including growth measures were performed by nurses blinded to group status. For height, infant length was measured using a paper tape, and when the child could stand, a staidiometer attached to the wall was used with the child in stocking feet. For weight, we used a balanced scale measured to the $1 / 4$ pound. After infancy, children were weighed while wearing minimal clothing. The measurement was written in the chart in pounds and inches, and later converted using ANTHRO. Pubertal development at age 12 years was determined by the child's self-assessment of Tanner's standard photographs (Tanner, 1962). This selfassessment was validated during health interviews with the parent(s). Adolescent assessment is accurate and has excellent concordance with professionals (Duke, Litt, \& Gross, 1980). Parent height was self-reported.

\section{Analytic Strategy}

We used $z$ scores in the longitudinal analysis because they are a more precise assessment of growth than percentile cut-offs and better quantify growth at the extremes of the distribution (Kuczmarski et al., 2002). They are preferable for statistical comparisons over time with fewer violations of the underlying assumptions than would occur if percentiles were compared by 
parametric statistics. A $z$ score of 0 equals the median (50th percentile), and a score of \pm 2 standard deviations (SDs) approximates the 98th and 2nd percentile, respectively.

Analysis of variance (ANOVA) was used to verify the a priori neonatal morbidity group classification for the neonatal variables at the first time point. Height, weight, and BMI percentiles $z$ scores with $95 \%$ confidence intervals (CIs) were calculated for each time point. We tested whether height and weight were significantly different between boys and girls at each time point. Only at birth did the girls $(M=-2.9 z$ score; $S D=2.1)$ have a higher weight than boys $(M=-3.7 z$ score; $S D=2.2)$. With only one difference, the sexes were combined to increase statistical power for the trajectory analysis. BMI was calculated for boys and girls from age 30 months because reference values are not established for children younger than 2 years. We examined the number of children who were below the third percentile as a gauge of poor growth.

To answer the first aim of whether growth was different for the preterm groups compared with the FT group, a mixed effects linear model was used to model the nonindependence of observations within subjects over time using an unstructured covariance matrix (Bryk \& Raudenbush, 1992; Short et al., 2003). With this method, we modeled height and weight as a function of neonatal morbidity group, age, linear and quadratic parameters for age (to detect nonlinear trajectories), and the interactions between neonatal morbidity and the age terms using SAS version 8.2 for UNIX (SAS Institute, Cary, NC). Successive model testing with interaction terms were tested, but were only used if significant (at the 0.05 level). These interactions determine if growth over time differs between the FT and preterm neonatal morbidity groups. Univariate analysis with ANOVA followed the significant models. Next, birth weight, using birth weight groups of ELBW $(<1000 \mathrm{~g})$; VLBW $(<1000 \mathrm{~g}$ and $<1500 \mathrm{~g})$; low birth weight ( $\mathrm{LBW},<1500 \mathrm{~g}$ and $<2500 \mathrm{~g}$ ); and FT ( $>2500 \mathrm{~g}$ ) was added to the models to answer the second aim of whether birth weight modified the effects of the neonatal morbidity exposures.

\section{RESULTS}

\section{Neonatal Morbidity Groups}

Five groups were enrolled as follows: 46 healthy FT infants, 29 HPT infants, 56 MPT infants, 34 NPT infants, and 29 SGA preterm infants. Table 1 illustrates the coherence of the a priori criteria with the final sample characteristics. The range of Hobel neonatal risk scores $(0-160)$ included all levels of risk from none to very high. The sample was $88 \%$ White, $7 \%$ Hispanic, $5 \%$ Black, and 50\% male. Mean maternal age was 27 years $(S D=6)$, with most completing high school $(M=13$ years; $S D=1.8)$ and $79 \%(n=136)$ married or living with their partners. SES (Hollingshead, 1975) was not different between groups over the six time points. Parental height was not significantly different across study groups (Table 1).

There was variability in the sample size over the six time points, though our retention rates were high, ranging from $88 \%$ to $97 \%$. Follow-up rates at age 12 years were $93 \%$ for the FT group, $100 \%$ for the HPT group, $91 \%$ for the MPT group, 91\% for the NPT group, and $93 \%$ for the SGA group. Maternal height, paternal height, and infant intake of kilo-calories per kilogram per day ( $\mathrm{kcal} / \mathrm{kg} / \mathrm{day})$ at hospital discharge were not significantly different across groups. There were no significant differences for pubertal stage across neonatal morbidity groups (boys: $X^{2}[32]=39.37, P=.17$; girls: $\left.X^{2}[36]=33.8, P=.57\right)$. Sixty percent $(n=51)$ of the boys and $50 \%(n=48)$ of the girls were Tanner stage 0 , while only $1.6 \%$ of the boys $(n=2)$ and $1 \%$ of the girls $(n=1)$ were Tanner stage 5 , thus illustrating early pubertal development of the sample at age 12 years.

Ten children had a diagnosis of cerebral palsy and/or developmental disability, and their growth was impaired. Some children had oral motor difficulties that may have inhibited adequate 
nutrition. We measured children who were wheelchair bound when we could or used the pediatrician's weight and height or maternal report. In the analysis, we have included and excluded these children, with no difference in the results. The results are presented for the full sample.

\section{Height, Weight and BMI of the FT Group}

The mean height and weight $z$ scores of the FT group remain near 0 or the 50th percentile from birth to age 12 years, while the $95 \%$ confidence intervals were within $.50 z$ score $(S D=.5)$ until ages 8 and 12 years. The $95 \% \mathrm{CI}$ for the sample for height were: birth, .43 to -.2018 months, -51 to $.56 ; 30$ months, -.07 to $.71 ; 4$ years, -.62 to $.56 ; 8$ years, -.44 to .45 ; and 12 years, -.41 to .40 . The $95 \%$ confidence intervals for weight were: birth, .68 to $.11 ; 18$ months, -.52 to $.37 ; 30$ months, -.53 to $.23 ; 4$ years, -.21 to $.50 ; 8$ years, -.01 to .76 ; and 12 years, .25 to 1.04 (Figures 1 and 2). The BMI mean scores for the FT boys and girls were within the expected norms for age and sex with higher mean BMI at ages 8 and 12 years (Table 2). No child was below the third percentile at ages 8 and 12 years. For the boys, the $95 \%$ CI range widened from 1 point at the younger ages to 2 points at ages 4 and 8 years and 4 points at age 12 years. The range of the $95 \% \mathrm{CI}$ for the girls was slightly less than 2 points at birth and 30 months, and then widened to 2.7 and 3.9 points at ages 8 and 12 years.

\section{Height of the Healthy, Medical, Neurologic, and SGA Preterm Groups}

For all the preterm groups, there were sharp increases in height between birth and 18 months (see Figure 1). In the HPT group (Figure 1A), the mean height $z$ score fell slightly from 18 months to 4 years, then increases steadily to age 12 years. The upper $95 \% \mathrm{CI}$ reaches $0 z$ score at 18 months (95\% CI: .18 to -1.15 ), 30 months (95\% CI: -.01 to -1.24$)$, and age 4 years (95\% CI: -.04 to -1.1 ). Although the mean values were lower, the MPT group (Figure 1B) followed the height trajectory pattern of the FT group, which slightly increased at 30 months (95\% CI: 0.2 to -0.6 ), then slightly decreased until age 4 years ( $95 \%$ CI: -.25 to -.94 ), remained steady at $-.5 z$ score $(95 \%$ CI: -.22 to -.83 ) at age 8 years, then rose to $-.19 z$ score at 12 years $(95 \%$ CI: .12 to -.47). The width of the $95 \%$ CI was narrower than the HPT group, with the upper 95\% CI limit near $0 z$ score from age 18 months. The NPT group (Figure 1C) had the shortest mean length $z$ score of all groups at birth $(-5.67,95 \%$ CI: -5.15 to -6.19$)$, the mean height $z$ score increased to -.08 (95\% CI: .61 to -.78$)$ at 30 months, fell to -.58 (95\% CI: -.22 to -1.47 ) at age 4 years, and -.65 (95\% CI: -.15 to -1.15$)$ at age 8 years, then rose to -.28 (95\% CI: . 21 to -.77 ) at age 12 years. After the sharp rise from birth to 18 months, the SGA preterm group mean $z$ scores were the lowest of all preterm groups between 18 and 144 months, remaining near -1.0 (Figure 1D). The range of the $95 \%$ CI varied from -.44 to -1.89 at 30 months, to -.64 to -1.36 at age 8 years, then widened again at age 12 years to -.29 to -1.6 . The upper $95 \%$ CI were no higher than $0 z$ score.

\section{Weight of the Healthy, Medical, Neurologic, and SGA Preterm Groups}

Weight gain for all the preterm groups sharply increased from birth to 18 months. For the HPT group (Figure 2A), the mean weight $z$ score rose to -.18 (95\% CI: 0.6 to -0.97 ) at 18 months, then decreased to $-1.0 z$ score (95\% CI: -0.42 to .1 .5 ) at 30 months, then increased steadily to age 12 years (mean $=.78 ; 95 \% \mathrm{CI}:-0.3$ to 1.5$)$ to surpass the FT group after age 8 years. A wide range existed in the 95\% CI across the time points. For the MPT group (Figure 2B), the mean weight $z$ score increased to -.97 (95\% CI: -0.7 to -1.28 ) at 18 months, then steadily increased across time, not reaching $0 z$ score until age 12 years (95\% CI: .33 to -.33 ). The upper $95 \% \mathrm{CI}$ were below $0 z$ score until age 8 years (mean -.17 , 95\% CI: .14 to -0.48 ). The NPT group (Figure 2C) had the lowest mean weight $z$ score at birth of the preterm groups. The mean weight increased to -.82 at 18 months (95\% CI: -.36 to -1.43 ), fell to -1.02 (95\% CI: -.42 to -1.5$)$ at 30 months, then returned nearing the 18 -month mean $(-.79 ; 95 \% \mathrm{CI}:-.41$ to 
$-1.24)$ at age 4 years, and continued to increase at ages 8 years (mean $=-.52,95 \% \mathrm{CI}:-.08$ to -.96 ) and 12 years (mean $=-.17,95 \% \mathrm{CI}:-.19$ to -.68$)$. The $95 \% \mathrm{CI}$ range was approximately $1 z$ score, and the upper limit CI did not reach $0 z$ score until age 8 years. The SGA preterm group (Figure 2D) mean weight $z$ scores are the lowest of all preterm groups between 18 and 144 months. At 18 months the mean was $-1.5 z$ score (95\% CI: -1.1 to -1.97$)$, and steadily increased across time to -.08 ( $95 \%$ CI: .26 to -.63 ) at age 12 years.

\section{BMI of the Healthy, Medical, Neurologic, and SGA Preterm Groups}

The mean BMI for the boys in the preterm groups were slightly below the FT group and the 50th percentile at 30 months (Table 2). The HPT, NPT, and SGA preterm groups were 1.6 points below the 50th percentile for age, while the MPT group was less than 1 percentile point (0.7). The mean differences below the 50th percentile were smaller by age 4 years, and fewer children were below the third percentile by age 8 years. By age 12 years, the BMI mean differences were above the 50th percentile, and only one boy in the HPT group and two boys in the NPT group were below the third percentile.

In contrast, the girls in the pre-term groups had mean BMI scores close to the age-specific mean at 30 months (Table 2). The MPT group had the lowest mean, while the NPT group had the highest mean. The mean differences for the preterm groups were all less than 1 percentile point. From age 4 years onward, the mean differences for the preterm groups were above the 50th percentile, and only 1 girl in each preterm group had a BMI score below the third percentile.

\section{Comparing Growth Trajectories between the FT and Preterm Groups}

Neonatal morbidity group had a significant effect on height trajectory over time $\left(X^{2}[20]=\right.$ $225.7, P<.0001$ ). The statistical interaction between neonatal morbidity and the quadratic parameter term confirmed that the curvilinear trajectory of the neonatal morbidity groups differs from the flat trajectory of the FT group. These trajectories are illustrated in Figures 1 and 2. The main effects of neonatal group and time were statistically significant. For this model, the intercept was $-4.8 z$ score. With the 1 unit addition of a FT group, height increased $4.9 z$ score, thus illustrating the $+0.1 z$ score mean of the reference population. The 1 unit addition of the HPT group increased height $1.17 z$ score, which when added to the intercept, yields a very low $z$ score of -3.6 . The 1 unit addition of the MPT group increased height $z$ score .09 , and the 1 unit addition of the NPT group decreased height $z$ score -.27 . Thus, for the preterm groups with medical or neurologic morbidity, there was reduced height. The negative sign for the interaction term indicates that for the preterm groups with neonatal morbidity, the positive effects of age (time) are reduced. The univariate analysis shows that the height $z$ score for the FT group had greater height than all the preterm groups until age 8 years, when the HPT group and MPT group had caught up. At the age 12 years assessment, only the SGA group had lower height compared with the other groups.

The neonatal morbidity group had a significant effect on weight trajectory over time $\left(X^{2}\right.$ [20] $=356.45, P<.0001)$. The statistical interaction between neonatal morbidity and the quadratic parameter term confirmed differences between the curvilinear trajectory of the neonatal morbidity groups and the flat trajectory of the FT group. For this model, the intercept was -4.4 $z$ score. With the 1 unit addition of an FT group, height increased $4.7 z$ score, thus illustrating the $+0.3 z$ score mean of the reference population. The 1 unit addition of the HPT group increased weight $.69 z$ score, which when added to the intercept, yields a very low $z$ score of -3.7 . The 1 unit addition of the MPT group increased weight $z$ score .06 , and the 1 unit addition of the NPT group decreased weight $z$ score -.27 . Similar to the height trajectory analysis, the preterm groups with medical or neurologic morbidity had lower weight and the positive effects of age (time). The univariate analysis shows that the weight $z$ score for the FT group had greater 
weight than all the preterm groups until age 4 years, when the HPT group weight was not different from the FT group. The significantly lower mean weight of the remaining three neonatal groups (MPT, NPT, SGA) compared with the FT and HPT groups remained at ages 8 and 12 years.

\section{Growth Trajectory Models with Birth Weight and Neonatal Morbidity}

Birth weight was added to the models to examine whether birth weight modified the effects of these neonatal morbidity exposures In the most parsimonious models, the main effect of birth weight and neonatal morbidity group were statistically significant for height trajectories $\left(X^{2}\right.$ $[20]=348.48, P=.0001)$, but only birth weight was significant for weight trajectories $\left(X^{2}[20]\right.$ $=473.81, P=.0001)$. The interaction between birth weight $\mathrm{x}$ neonatal morbidity was not significant for either the height or weight models. Thus there was not a multiplicative effect of neonatal morbidity and birth weight on height and weight trajectories through age 12 years.

For height, the intercept was -2.6 , the 1 unit addition of the SGA group slope decreased height $-3.7 z$ score, which when added to the intercept, yields a low $z$ score of -6.3 . The 1 unit addition of the HPT group slope decreased height $-2.0 z$ score, the 1 unit addition of the MPT group decreased height slope $-3.5 z$ score, and the 1 unit addition of the NPT group decreased height slope $-3.3 z$ score. The point estimate for the addition of birth weight group was not significant. For weight, the intercept was -2.6 , the 1 unit addition of the SGA group decreased weight slope $-2.8 z$ score, which when added to the intercept, yields a low $z$ score of -5.8 . The 1 unit addition of the HPT group decreased weight slope $-2.7 z$ score, the 1 unit addition of the MPT group decreased weight slope $-2.9 z$ score, and the 1 unit addition of the NPT group decreased weight slope $-3.1 z$ score. The point estimate for the 1 unit addition of birth weight group slightly increased weight slope $.72 z$ score. Thus, the addition of birth weight with neonatal morbidity, although statistically significant, had a relatively small effect on slopes for weight.

\section{DISCUSSION}

Our growth trajectory results show that neonatal morbidity exerts a continued effect on height and weight from birth to age 12 years. The mixed effects linear models were significant for the growth trajectories to age 12 years with a main effect of neonatal morbidity. The interactions indicate that preterm height and weight growth trajectories differ from the FT group. When plotting $z$ score means uncorrected for prematurity, we see the expected rapid increment in growth between birth and 18 months of age for all the preterm groups, followed by different fluctuations. For height, the FT group had statistically higher height than did the preterm groups to age 8 years, when the HPT and MPT groups caught up, so that at age 12 years only the SGA group had smaller height. For weight, the catch-up trajectory was slower. The HPT group had caught up by age 4 years, but the MPT, NPT, and SGA preterm groups continue to have lower weight through age 12 years. The SGA group had the lowest weight and the smallest height, reaching a group mean 34 th percentile by age 12 years. The BMI growth from 30 months to 12 years shows appropriate weight for height for preterm boys and girls with or without neonatal morbidity by age 4 years and very little evidence of being underweight. BMI has received increased attention for pediatric use to screen for over-weight adolescents and children, ages 2 years and older, and to characterize underweight (though no expert guidelines exist for the classification of underweight based on BMI).

Our growth trajectory results show that neonatal morbidity exerts a continued effect on height and weight from birth to age 12 years.

Hack and colleagues $(2003 ; 1996)$ monitored 195 VLBW children born between 1977-1979 to ages 8 and 20 years and reported that boys had lower height, weight and BMI, while girls had lower weight and BMI at age 8 years. These findings are in contrast to our data, where sex 
was not a significant factor differentiating growth trajectories to age 12 years. Only 10 children had experienced severe sequelae, making growth assessment difficult. The trajectory models remained significant when these children were removed from the models. Segmental measures as a proxy for height may be a worthwhile when comparable growth charts are available (Stevenson, 1995).

During the neonatal period, factors influencing growth include neonatal illness, birth weight, poor sucking, appetite, long hospitalization, and difficulty with maternal-infant interaction. In this study, infants were classified into neonatal morbidity groups at NICU discharge after the birth growth measures were taken. An unstable neonatal course may disrupt physiologic and regulatory systems, contributing to poorer feeding and subsequent growth. We know that during the course of the study, none of the children were rehospitalized for failure to thrive, had feeding tubes, or were malnourished according to our health history interview or pediatrician records. For this sample, hospital discharge data show no neonatal morbidity group differences in in-take of kilocalorie per kilogram per day. Our measurement of the intake of calories at discharge was taken at a time when the infants were fairly healthy and should have been similar across groups. Research approaches considering specific morbidities and calorie/ nutrient intake with regular growth measures may help us understand how much energy expenditures are drained for NICU survival and physiologic equilibrium at the expense of early growth.

There are consistent reports of SGA growth delay at ages 5 to 6 years from mid-1970s cohorts (Hadders-Algra \& Touwen, 1990). Hack et al. (1996) reported slower rates of catch-up for VLBW SGA preterm children at age 8 years, with more SGA boys than girls with subnormal weight and height. At age 14 years, Peralta-Carcelen and colleagues (2000) reported significantly lower height and weight in ELBW. Neonatal morbidities of apnea, BPD, IVH, sepsis, NEC, patent ductus arteriosis, and seizures were matched in the 1993 SGA versus appropriate for gestational age comparison study by Sung, Vohr, and Oh (1993). These children, born at the same time as our sample, had smaller height and weight at 1,2, and 3 years of age, but head circumference did not differ by age 3 years.

Despite neonatal morbidity grouping, at age 12 years, most of the boys and girls in the sample were in early stages of pubertal development. In the United States, the growth spurt accompanying puberty occurs at 12.2 years for girls and 12.6 years for boys, so the majority of the sample is still to experience this growth spurt and their adult height. Three reports from preterm cohorts born between 1977 and 1984, earlier than the present sample, found no FTpreterm differences in sexual maturity using the same measure, Tanner stages. Neither PeraltaCarcelen and colleagues (2000), who compared adolescents born ELBW and NBW at age 141/2 years, nor Ford et al. (2000), who compared ELBW, VLBW and NBW adolescents at age 14 years, nor Powls et al. (1996), who compared VLBW and NBW adolescents at age 12 years, found pubertal development differences. Collectively, these results contradict reports of preterm children born in the 1970s of early sexual maturity for children born prematurely (Nelson, 1983).

The addition of birth weight to the models showed a main effect, not an interaction effect, of neonatal morbidity for height and weight trajectories. Birth weight added only a small effect to the models for weight trajectories. Powls et al. (1996) tested the effect of birth weight, birth weight for gestational age, gestation, sex, cystic periventricular leukomalacia, IVH (grade 2 or above), and neonatal convulsions on age 12 years height and reported only $3 \%$ variance accounted by one variable, birth weight for gestational age. Hack et al. (2003) found birth weight $z$ score and duration of neonatal hospitalization to be a significant predictor of 20-year growth attainment. Follow-up studies have reported on cohorts born in the late 1970s and early 1980s (Ford, 2000; Hack et al., 2002; Hack et al., 1996; Peralta-Carcelen et al., 2000; Saigal, 
2001). Our sample was recruited at birth between 1985-1989 and grouped by neonatal morbidity, with a wide range of preterm birth weight (640 to $1800 \mathrm{~g}$ ) and a FT comparison group. While it is assumed that there is greater neonatal morbidity with smaller birth weight, children with larger birth weight also may have neonatal illness.

Some persons suggest that prematurity induces alterations in metabolism that may result in later obesity, with higher adult risk for cardiovascular changes and adult onset diabetes (Law, 2001). In a recent systematic review, a $z$ score change less than .67 between two different childhood ages was considered rapid growth, and rapid growth was associated with later obesity (Monteiro \& Victora, 2005). Epidemiologic evidence from Britain and Finland shows this combination is associated with increased risk for adult coronary artery disease in adulthood, especially for males (Erikson, Forsen, Tuomelihto, Osmond, \& Barker, 2001; Law). Reduced growth has been shown to increase the risk of hypertension, diabetes, and high cholesterol, suggesting the fetal origins hypothesis that cardiovascular disease may result from the infant's response to undernutrition, which permanently changes body physiology and structure. It will be important to prospectively follow these preterm cohorts into adulthood to further test this hypothesis.

Hack et al. (2003) found that VLBW males remained shorter and weighed less at age 20 years. Kitchen, Doyle, Ford, and Callanan (1992), who monitored 269 VLBW, ELBW, and NBW children born in 1977-1982, reported that ELBW and VLBW children were shorter at 2, 5, and 8 years of age and weighed less at ages 2 and 5 years than did the NBW comparison. Height increments for ELBW and VLBW boys between 5 and 8 years were smaller than the increments for girls, and the ELBW group had higher incidence of neonatal morbidity including seizures, IVH, BPD, retinopathy of prematurity, and NEC. For neonatal morbidity variables, only birth weight predicted age 8 year weights below the 10th percentile, while only maternal height predicted age 8 year heights. In a follow-up study, only birth weight less than $1000 \mathrm{~g}$ and parental height was associated with short stature (Doyle, Ford, Abadilla, Warne, \& Callanan, 1993). At age 14 years, the VLBW group had later catch-up weight from age 8 years compared with the NBW group; although still lighter ( $\operatorname{girls}=7.3 \mathrm{~kg}$; boys $=8.3 \mathrm{~kg}$ ), they remained shorter by $4.5 \mathrm{~cm}$ for girls and $5.8 \mathrm{~cm}$ for boys (Doyle, 2000). Powls et al. (1996) reported a mean VLBW height difference of $4.1 \mathrm{~cm}$ at age 12 years. We found larger differences compared with the FT group for the SGA boys $(6.4 \mathrm{~cm})$, SGA girls $(8.5 \mathrm{~cm})$, MPT boys $(5.8 \mathrm{~cm})$, and NPT boys $(5.3 \mathrm{~cm})$. Saigal (2001) also found catch-up growth between ages 8 and $12-16$ years of 154 ELBW and 125 term control subjects born between 1977-1982. At age 8 years, the ELBW group was significantly smaller in height, weight, and head circumference, but with improvement, girls had more gain than boys at adolescence.

We decided to use ANTHRO because of the large volume of data and its facility to calculate percentiles and $z$ scores. We recognize that the 1977-1978 growth charts are based on a primarily White national sample. However, our sample was born between 1985 and 1989, is representative of NICU admissions of this time, and is primarily White. Using $z$ scores in the mixed effects models to examine growth indicated that our FT group was a normal comparison and illustrated how the prematurely born children normalized with time in height and weight.

Unique aspects of this study include the sample and design with prospective classification by neonatal morbidity, SES stratification, longitudinal design with regular assessment intervals, long duration of follow-up, and a very high compliance rate. Unlike many preterm follow-up studies, this study sample was recruited specifically for research purposes, not health service delivery, thus following research standards in its protocols. This is an important distinction because little is known about potential differences in the quality of data collected in clinical follow-up versus research settings (Lester \& Miller-Loncar, 2000). Birth dates for the sample are 1985-1989, a transition time for neonatal technologies such as surfactant and postnatal 
steroids. Longitudinal preterm growth studies to school-age and early adolescence include children born from the late 1970s and early 1980s, thus the present study extends our knowledge of preterm growth in the context of late 1980s NICU technologies and its relationship to various neonatal morbidities and birth weight. Survival rates for preterm infants have increased, but the incidence of neonatal morbidity has remained constant; thus these findings are relevant for current NICU survivors. We concur with Doyle (2000) that the outcomes of cohorts of the immediate past reflect NICU practices of the time. Nevertheless, they are our best source for how preterm infants born today and cared for with newer NICU technologies may progress in growth at later ages.

\section{Implications for Clinical Practice}

Given the growing numbers of premature infants, more clinicians will be caring for children who were born prematurely with various types of perinatal morbidity. Our results highlight that the health history include details of the NICU course, neonatal diagnoses, and discharge summary. Because many infants require multiple medical specialists, allied health therapists, and participate in intervention programs, Kelly (2006) suggests that families keep a shadow chart that serves to keep pediatric professionals updated.

Serial measures of height, weight, BMI, and head circumference are important in preterm infant follow-up, not only to identify adequate growth, but to evaluate the trajectory for infants who had particular neonatal morbidities. A clinical application of these findings would incorporate how neonatal morbidities and birth weight inform weight and height fluctuations at different ages. Helping parents anticipate rapid growth in the first 12 to 18 months followed by varying rates of catch-up in the preschool and school-age years may reduce concerns about their child's health. Adequate nutrition and feeding problems are common parental concerns, which can be complicated by oral sensory, medical, and behavioral issues. An overlay to mark the timing of intervention for these issues would further enlighten plotted growth trajectories. BMI was appropriate for the majority of premature children in this sample. Using BMI to determine overweight will be an important anticipatory strategy as the child reaches adolescence and young adulthood. The six areas identified in the HEAT initiative (NAPNAP, 2006) are evidence-based strategies to prevent the tendency of low birth weight infants to have adult overweight and obesity.

\section{Acknowledgments}

The statistical expertise of Stephen Faraone, PhD, and Amy Marks, PhD, is kindly acknowledged.

This work was supported by National Institute of Health grant Nos. NICHD 191985, NINR 530110, NINR 530205, and NINR 530209.

\section{REFERENCES}

Albertsson-Wiklund K, Karlberg J. Natural growth in children born small for gestational age with and without catch up growth. Acta Paediatrica 1994;399:64-70.

Babson SG, Benda GI. Growth graphs for the clinical assessment of infants of varying gestational age. Journal of Pediatrics 1976;89:814-820. [PubMed: 978333]

Bell MJ, Ternberg JL, Feigin RD, Keating JP, Marshall R, Barton L, et al. Neonatal necrotizing enterocolitis: Therapeutic decisions based on clinical staging. Annals of Surgery 1978;187:1-7. [PubMed: 413500]

Bryk, AS.; Raudenbush, SW. Hierachical linear models: Applications and data analysis methods. Sage Publications; Newbury Park, CA: 1992.

Doyle LW. Growth and respiratory health in adolescence of the extremely low-birth weight survivor. Clinics in Perinatology 2000;27:421-432. [PubMed: 10863658] 
Doyle LW, Ford GW, Abadilla GL, Warne GL, Callanan C. Assessment of short stature in very low birthweight children. Journal of Paediatric Child Health 1993;29:411-414.

Duke PM, Litt IF, Gross RT. Adolescents' self-assessment of sexual maturation. Pediatrics 1980;66:918920. [PubMed: 7454482]

Erikson JG, Forsen J, Tuomelihto J, Osmond C, Barker DJP. Early growth and coronary heart disease in later life: Longitudinal study. British Medical Journal 2001;322:949-953. [PubMed: 11312225]

Ferber S, Kuint J, Weller A, Feldman R, Dollberg S, Arbel E, et al. Massage therapy by mothers and trained professionals enhances weight gain in preterm infants. Early Human Development 2002;67:3745. [PubMed: 11893434]

Ford GW, Doyle LW, Davis NM, Callanan C. Very low birth weight and growth into adolescence. Archives in Pediatric and Adolescent Medicine 2000;154:778-784.

Hack M, Flannery DJ, Schluchter M, Cartar L, Borawski E, Klein N. Outcomes in young adulthood for very-low-birth-weight infants. The New England Journal of Medicine 2002;346:149-157. [PubMed: $11796848]$

Hack M, Schluchter M, Cartar L, Rahman M, Cuttler L, Borawski E. Growth of very low birth weight infants to age 20 years. Pediatrics 2003;112:e30-e38. [PubMed: 12837903]

Hack M, Weissman B, Borawski-Clark E. Catch-up growth during childhood among very low-birthweight children. Archives of Pediatric Adolescent Medicine 1996;150:1122-1129.

Hadders-Algra M, Touwen BCL. Body measurements, neurological and behavioral development in sixyear-old children born preterm and/or small for gestational age. Early Human Development 1990;22:1-13. [PubMed: 2335139]

Hobel CJ, Hyvarien M, Okada D, Oh W. Prenatal and intrapartum high risk screening. American Journal of Obstetrics and Gynecology 1973;1:117.

Hollingshead, AB. Four factor index of social status. Yale University Press; New Haven, CT: 1975.

Kelly MM. The medically complex premature infant. Journal of Pediatric Health Care 2006;20:367-373. [PubMed: 17071367]

Kitchen WH, Doyle LW, Ford GW, Callanan C. Very low birth weight and growth to age 8 years II. Head dimensions and intelligence. American Journal of Diseases of Children 1992;146:46-50. [PubMed: 1736648]

Kuczmarski RJ, Ogden CL, Guo SS, Grummer-Strawn LM, Flegal KM, Mei Z, et al. 2000 CDC Growth Charts for the United States: Methods and development. Vital Health Statistics 2002;11:1-190.

Law C. Adult obesity and growth in childhood. British Medical Journal 2001;323:1320-1321. [PubMed: 11739206]

Lester, BM.; Miller-Loncar, CL. Biology versus environment in the extremely low-birth weight infant. In: Vohr, BR., editor. Clinics in perinatology: Outcomes of the very low-birth weight infant. Vol. Vol. 27. W.B. Saunders Co.; Philadelphia: 2000. p. 461-482.

Lubchenco LC, Hansman C, Boyd E. Classification of newborns based on maturity and intrauterine growth. Pediatrics 1966;37:403. [PubMed: 5906365]

Monteiro POA, Victora CG. Rapid growth in infancy and childhood and obesity in later life. Obesity Reviews 2005;6:143-154. [PubMed: 15836465]

Moyer VA, Klein JD, Ockene JK, Teutsch SM, Johnson MS, Allan JD. Screening for overweight in children and adolescents: Where is the evidence? A commentary by the Childhood Obesity Working Group of the US Preventive Services Task Force. Pediatrics 2005;116:235-238. [PubMed: 15995061]

National Association of Pediatric Nurse Practitioners. Healthy eating and activity together (HEAT) clinical practice guidelines: Identifying and preventing overweight in childhood. Journal of Pediatric Health Care 2006;20(Suppl 1):1-64.

Nelson KG. Premature thelarche in children born prematurely. The Journal of Pediatrics 1983;103:756758. [PubMed: 6631606]

Papile LA, Burstein J, Burstein R, Koffler H. Incidence and evaluation of subependymal and intraventricular hemorrhage: A study of infants with birth weights less than 1,500 gm. The Journal of Pediatrics 1978;92:529-534. [PubMed: 305471] 
Peralta-Carcelen M, Jackson DS, Goran MI, Royal SA, Mayo MS, Nelson KG. Growth of adolescents who were born at extremely low birth weight without major disability. Journal of Pediatrics 2000;136:633-640. [PubMed: 10802496]

Powls A, Botting N, Cooke RWI, Pilling D, Marlow N. Growth impairment in very low birthweight children at 12 years: Correlation with perinatal and outcome variables. Archives of Disease in Childhood 1996;75:F152-F157. [PubMed: 8976679]

Ross G, Lipper E, Auld P. Growth achievement of very low birth weight premature children at school age. Journal of Pediatrics 1990;117:307-309. [PubMed: 2380832]

Saigal S, Stoskopf BL, Striener DL, Burrows E. Physical growth and current health status of infants who were of extremely low birth weight and controls at adolescence. Pediatrics 2001;108:407-415. [PubMed: 11483807]

SAS Institute. SAS/STAT User's Guide, Version 6. Vol. Vol. 2. SAS Institute; Cary, NC: 1989.

Short EJ, Klein NK, Lewis BA, Fulton S, Eisengart S, Kercsmar C, et al. Cognitive and academic consequences of bronchopulmonary dysplasia and very low birth weight: 8-year-old outcomes. Pediatrics 2003;112:359-366. [PubMed: 12897287]

Stevenson RD. Use of segmental measures to estimate stature in children with cerebral palsy. Archives of Pediatric \& Adolescent Medicine 1995;149:658-662.

Sullivan, KM.; Gorstein, J. ANTHRO: Software for calculating anthropometry (Version 1.02) [Computer software]. Centers for Disease Control and Prevention; Atlanta, GA: 1999.

Sung I, Vohr B, Oh W. Growth and neurodevelopmental outcome or very low birth weight infants with intrauterine growth retardation: Comparison with control subjects matched by birth weight and gestational age. Journal of Pediatrics 1993;123:618-624. [PubMed: 7692029]

Tanner, JM. Growth at adolescence. 2nd ed.. Blackwell Scientific Publications; Oxford: 1962.

Vrlenich LA, Bozynski MEA, Shyr Y, Schork A, Roloff DW, McCormick MC. The effect of bronchopulmonary dysplasia on growth at school age. Pediatrics 1995;95:855-859. [PubMed: 7761209] 

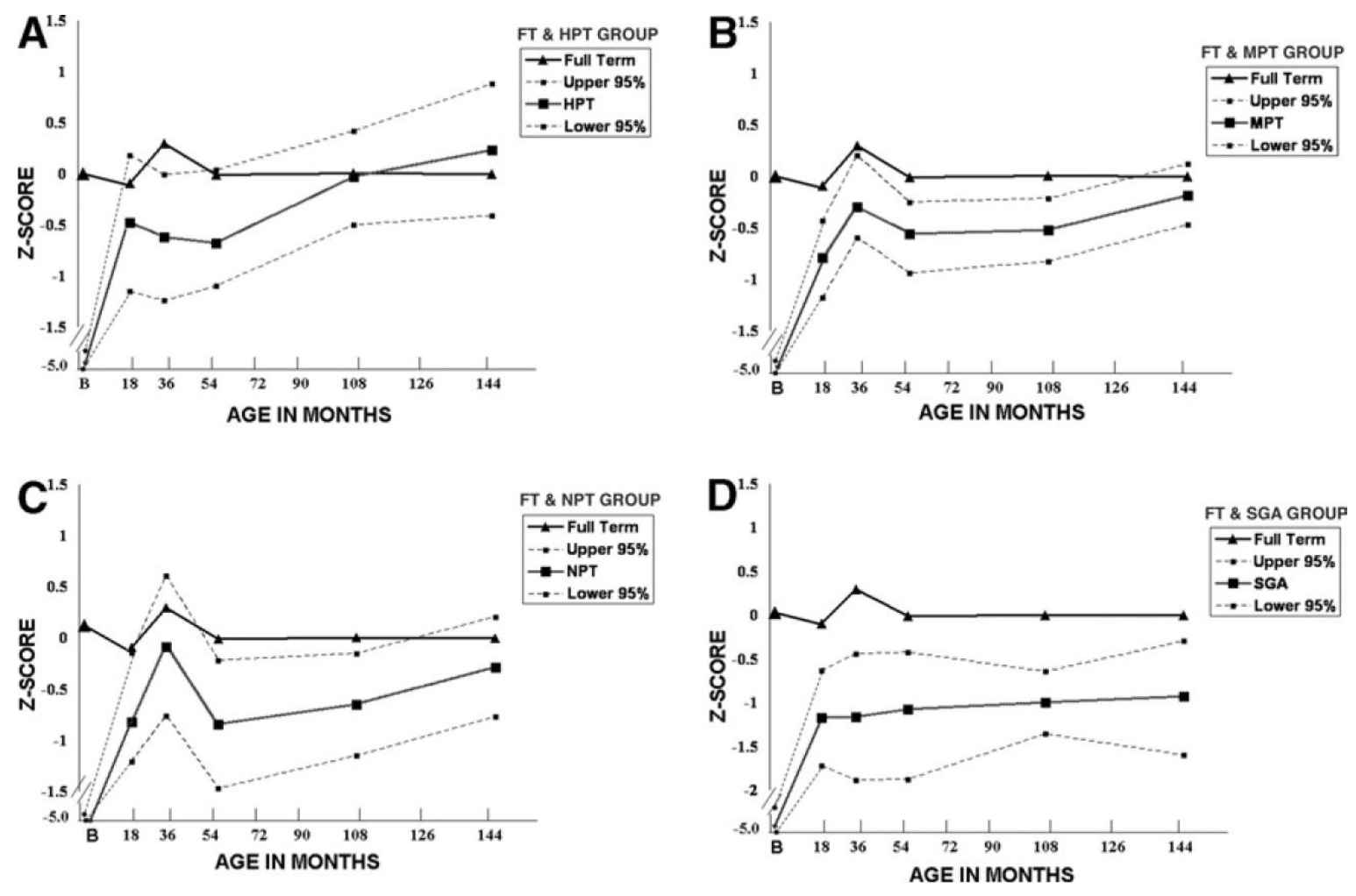

FIGURE 1.

Comparing Full Term Height $z$ Scores with the Preterm Groups 

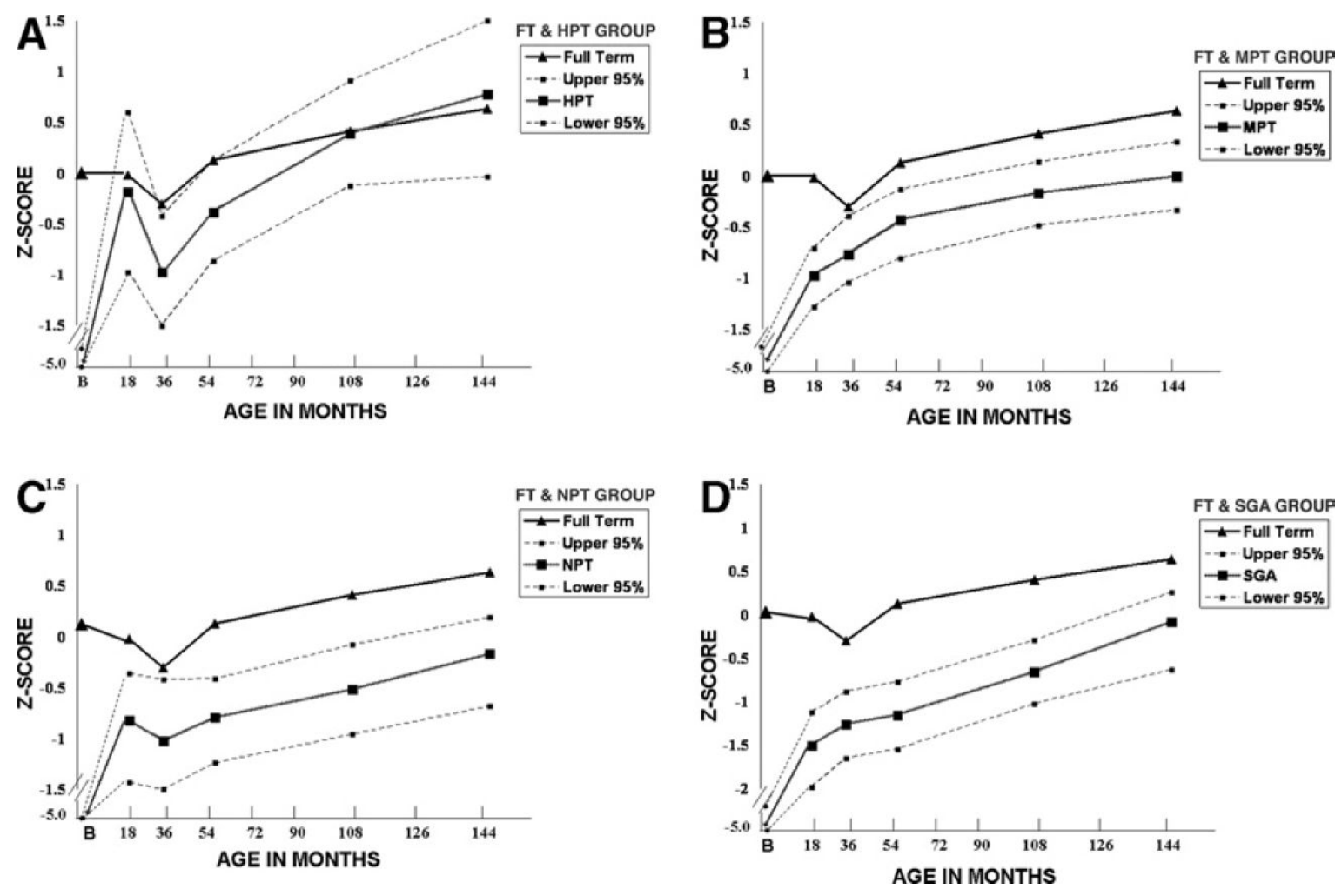

FIGURE 2.

Comparing Full Term Weight $z$ Scores with the Preterm Groups 


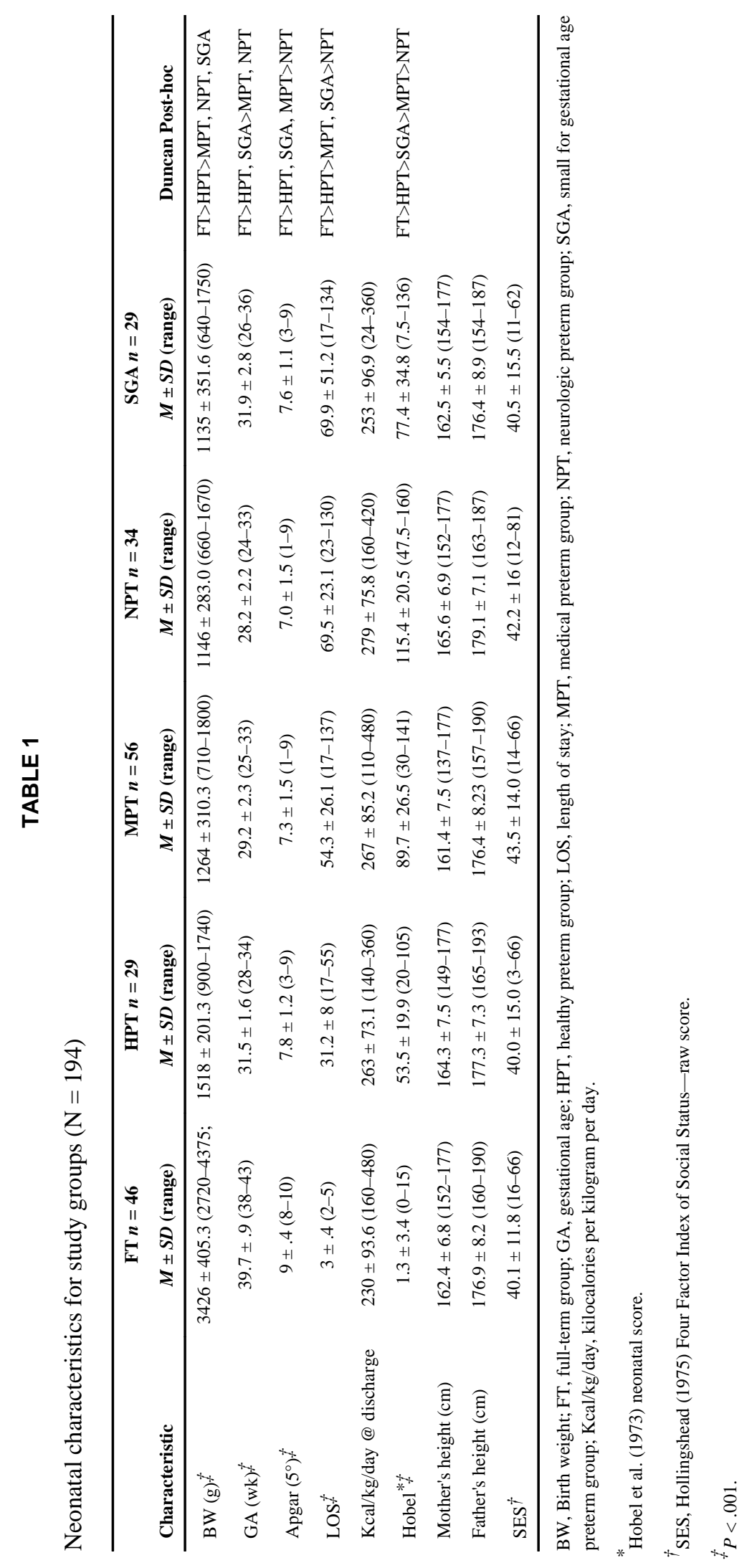

J Pediatr Health Care. Author manuscript; available in PMC 2010 February 12. 


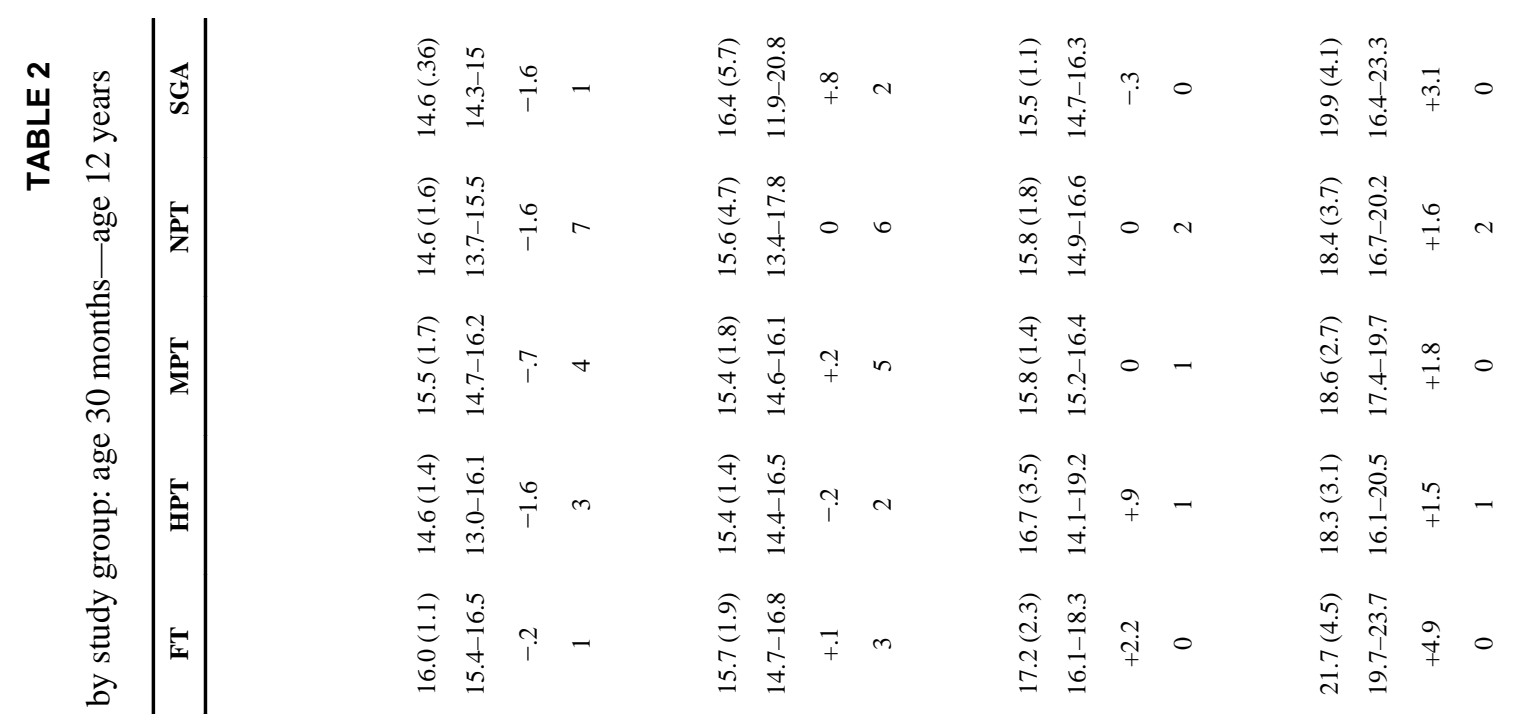


